\title{
The Quality of Parent-Teacher Relationship Scale in the Kindergarten: A Greek Study
}

\author{
Konstantinos Petrogiannis (Corresponding author) \\ School of Human Sciences, Hellenic Open University \\ Aristotelous 18 lane, Patras 26335, Greece \\ E-mail: kpetrogiannis@eap.gr
}

\begin{abstract}
Efthymia Penderi
Pireos 9 Str., Kavala 65404, Greece

E-mail: effieped55@gmail.com
\end{abstract}

Department of Education Studies in the Preschool Age, Democritus University of Thrace

Received: October 1, 2013 Accepted: November 4, 2013 Published: November 22, 2013

doi:10.5296/ire.v2i1.4343 URL: http://dx.doi.org/10.5296/ire.v2i1.4343

\begin{abstract}
The present study elaborates on the issue of the relationship quality between parents and teachers. It focuses on kindergarten as it constitutes an educational context that addresses unique challenges for parent-teacher interaction and there is a lack of measurement tools to capture the affective dimensions of this interaction. A newly constructed measure is presented, the Quality of Parent-Teacher Relationship Scale in the kindergarten (QPTRS-K) which was developed on the basis of four quality indicators that were proposed. A nationally selected sample of 913 mothers and 233 kindergarten teachers provided data for the QPTRS-K corresponding forms. Moreover, participants provided information about a set of theoretically-linked variables to examine reliability and validity issues. Two factors emerged that were interpreted as Trust/Acceptance and Communication/Responsiveness, providing evidence for the conceptual considerations of the scale development. Mothers and teachers' total scores and subscales had high internal consistency. The relations with the proposed variables and the direction of the links were indicative of the validity of the scale. Implications concerning policy and research are discussed.
\end{abstract}


Keywords: Greece, kindergarten, quality of parent-teacher relationship

\section{Introduction}

Family-school interaction has been longitudinally one of the most favorite themes in the psycho-educational research literature and constitutes a field of abundant theoretical dialogue and empirical work. A critical issue, among a plethora of others, is parental involvement and the development of substantial, reciprocal and trusting parent-teacher relationships, which have been found to be related with children's development and learning. Especially nowadays, this interaction is of critical importance for children's optimal development and learning due to the dramatic changes in societal conditions of parenting during the last decades (Hujala, Turja, Gaspar, Veisson, \& Waniganayake, 2009; Rimm-Kaufman \& Pianta, 2000). For example, Smith and Hubbard (1988) argue that when parents and teachers relate well and develop a good relationship based on supportiveness, reciprocity and balance of power, children feel more comfortable with the teacher, are more talkative, happy and well-adjusted in the preschool environment. Accordingly, Reynolds, Weissber and Kasprow (1992) found that the qualitative aspects of parental involvement reported by teachers (e.g., satisfaction with parent-teacher contact and their overall working relationship), rather than the quantitative (e.g. frequency of parents' participation in school activities), predicted kindergartners and 1st graders' early adjustment in the school context.

On the other hand, a negative aspect of this relationship may be related with parents' perceptions of school as unwelcoming and feeling threatened in engaging in communication with teachers (Mannan \& Blackwell, 1992) or this communication may be triggered by negative experiences with school personnel that usually lack the skills to be effective in their interaction with parents and the "punitive" nature of contact which is usually initiated over the child's behavioral or academic problems (Baker, 1997; McBride, 2003). With regard to teachers, they may feel vulnerable and professionally threatened by parents' increased presence in the school setting (Addi-Raccah \& Ainhoren, 2009).

Especially with reference to the preschool period, it is acknowledged that parent-teacher collaboration is very critical especially during the early years due to the importance of children's transitions from home to a preschool setting or from preschool to elementary school (McWayne at al., 2004).

Little is known about the qualitative characteristics of parent-teacher interaction, while kindergarten remains, from an empirical research point of view, almost an uncharted field (Pirchio, Volpe, \& Taeschner, 2011). It should be noted that very few studies have addressed the issue of parent-teacher relationship and focused mainly on preschool settings (day care or nurseries). For example, Sakellariou and Rentzou (2008) found that parents and caregivers in Greek day-care centers do not actually communicate frequently to exchange information about the children. Their contact is limited to informal exchanges during arrival and departure and communication focuses mainly on nourishment and children's participation in activity issues. Their interaction was generally characterized as respectful and positive. Rentzou (2011) used Elicker and associates' methodology (1997) to measure parents and caregivers' relationship quality, recording more or less similar results to other relevant international 
studies. In general, it was argued that preschool did not favor parental participation while relationship with caregivers seemed to be positive but superficial.

There is also lack of measurement tools that capture the distinctive characteristics of the relational and affective expressions of family and kindergarten connections. Existing research seems to methodologically consolidate kindergarten with the other primary grades using the same measurements and presenting results in a unified way (Conduct Problems Prevention Research Group, 1995; Kohl, Lengua \& McMahon, 2000; Vickers \& Minke, 1995). Moreover, most of the studies targeting on the relational aspect of family-school interaction focuses mainly on the issue of barriers in parent-teacher communication and collaboration using qualitative methodologies that may shed light to the core of the problematic issues concerning this interaction but fail to depict the level and the dimensions, of the relationship quality between parents and teachers. The use of measurement tools that could provide data across a wide range of participants would help researchers gain knowledge about how agents understand and evaluate their relationship so as to further investigate the problematic areas of this relationship and chart the participants' suggestions.

In Greece the issue of parental involvement has only recently gained theoretical and empirical interest since/as educational, until recently, policy had not supported parents' active participation in the school setting. A recent educational law concerning mandatory attendance of the five-year old children in the kindergarten (Educational Act 3518/21-12-2006) and guidelines in the new kindergarten curriculum (Alevriadou et al., 2008; Dafermou, Koulouri, \& Basagianni, 2006; Pedagogical Institute, 2011a) that emphasize parental participation in the educational activities and close parent-teacher communication and collaboration, are among the issues that prioritize the examination of both the quantitative and qualitative aspects of home-kindergarten connection to inform policy and interventions. It could be argued that the new developments in the kindergarten curriculum concerning parents and kindergarten teachers' contact and collaboration are the most innovative in the Greek educational reality with reference to the issue of family-school interaction. From an empirical point of view the focus of existent research is on the types of parental involvement, the context and the extent of parent-teacher communication.

Parent-teacher communication in the kindergarten seems to be one of the most difficult aspects to handle, at least from the teachers' perspective (Rekalidou \& Penderi, 2010). It is argued that parents are in general satisfied with the way and the extent that kindergarten teachers interact with them (Mousena \& Papaprokopiou, 2009). However, Manolitsis (2004) found that parent-teacher contact was the least reported form of parental involvement by the parents. It is reported that when parents communicate with kindergarten teachers they usually want to exchange information about the child's behaviour, learning or safety-hygiene matters, while teachers contact parents to provide information about the program and the activities in the classroom, to ask their help and support, or to ask questions about the child's progress and development (Papandreou, Birbili \& Martidou, 2009). However there is no study focusing on the issue of the relationship quality between parents and kindergarten teachers in Greece. 


\subsection{Towards Conceptual Specification of Parent-Teacher Relationship Quality}

Powell and associates (2010) argued that the quality of relationship between parents and teachers is a multidimensional construct that consists of related but distinct elements of interpersonal relationships such as responsiveness and communication ease. Based on the review of the relevant literature, the basic elements of parent-teacher relationship that constitute its unique character could be organized in four aspects of their interaction, namely:

i. Nature of interaction. Relationship involves a series of interaction over time and both the frequency and components of interaction affect the nature of relationship and vice versa (Hinde, 1995). It is argued that close relationship are characterized by high levels of trust and intimacy (Miller \& Lefcourt, 1983). In order to reach these levels, a stable communication, emotional responsiveness and reliance are some necessary criteria that according to Lasky (2000) are not met in the context of parent-teacher interaction. In fact, in many educational settings this interaction is occasional, brief and it takes place during structured meetings while it does not always involve interpersonal communication (e.g., Patrikakou \& Weissberg, 2000).

The parent-teacher relationship is usually developed over the course of a single school year or in some cases two. However, even in this context relational aspects appear and flourish as there is a commitment and dependence over a common purpose, there are expectations about performance and trustworthiness, there is certain flow of information through different lines and patterns of communication.

ii. Style of interaction. It is argued that the links between parents and teachers are so fragile, derogated by many tangible barriers involving power and control, that a single incident can create negative climate between them and even abate willingness for communication (Lasky, 2000; Phtiaka, 1999). In addition differences in roles, expectations and concerns about the child's education are reported, especially with reference to elementary school, as sources of conflict and even rivalry between them (Addi-Raccah \& Arviv-Elyashiv, 2008). Consequently, the consideration of both positive and negative aspects of parent-teacher relationship when measuring its quality is not only methodologically proper, with respect to the participants' response style (Weijters, Geuens, \& Schillewaert, 2010) but also theoretically and conceptually useful, as it helps to capture the full spectrum of parent-tteacher interaction. Conflict is innate in relationship development (Hinde, 1995).

iii. Satisfaction of interaction. Relationship between parents and teachers develops in the course of interaction and communication that is triggered by their commitment to the promotion of children's education and wellbeing. Satisfaction is derived from the outcomes of this interaction that concern the children's academic and social performance while more personal benefits may also be met as partners could get positive feedback about their skills, behaviors and practices that are embedded in their professional and parenting roles and duties correspondingly, or even experience pleasure and satisfaction from interaction per se.

iii. Behavioral patterns underlying interaction. Collaboration and partnership between parents and teachers create the context that fosters effective relationships (Smith \& Hubbard, 
1988). Mutual respect for skills and knowledge, honest and clear communication, open and two-way sharing of information, mutually agreed-upon goals, shared planning and decision making are among the elements of collaboration that predicate trust between partners (Adams \& Christenson, 2000).

v. Developmental perspectives of interaction. All the aforementioned aspects of parent-teacher interaction seem to shift in accordance to children's developmental characteristics and educational needs, as well as the specific features of each educational setting which reflect these needs. For instance parent-teacher contact seems to decrease as the children enter to primary and high school (Flynn, 2007; Gonzalez-DeHass \& Willems, 2003). In elementary and secondary levels, parents and teachers seem to have limited contact and as a result there are few opportunities to develop sustained relationships (Lasky, 2000), while preschool is a more optimal context for the promotion of parent-teacher communication and collaboration (Powell et al., 2010). Differences in the extent and frequency of interaction may signal changes in the qualitative and quantitative aspects of relationships. For example, in elementary school two basic dimensions seem to frame parents and teachers affective experiences of their interaction (Vickers \& Minke, 1995). In preschool, though, a third dimension emerges that represent a close and more friendly and personal connection between parents and caregivers (see Elicker et al., 1997).

\subsection{The Main Elements of the Parent-Teacher Relationship Quality}

The quality of parent-teacher interaction is a complex concept as it refers to a process that involves both objective and subjective features of personal and interpersonal characteristics, behaviors, attitudes, believes and expectations that reflect the broader socio-cultural context in which they are embedded.

The relational and affective dimension of parent-teacher interactions has been mainly stressed by three lines of research: a) studies that emphasize on the emotional aspects of teaching and teacher development (for example Hargreaves, 2001; Sutton \& Wheatley, 2003), b) studies that focus on parental involvement in children's education (for example Kohl, Lengua, \& McMahon, 2000) and c) studies driven by eco-systemic perspectives that are interested in the developmental outcomes of adult-to-adult interactions (for example Elicker et al., 1997). Based on an extensive review of the empirical studies literature aforementioned, in an effort to define and measure the quality of relationship, a set of indicators could be used (Figure 1), namely:

i. the emotional tone of the relationship. It can be understood though the positive and negative feelings that parents and teachers experience during interaction, the general emotional impression from their contact as well as from their indirect connection which is established through the child and the experiences and ideas that are mediated from one context to the other.

ii. the affective blueprint of interaction. It reflects the levels of distance or closeness parents and teachers experience during interaction and communication.

iii. the behavioral regularities that reflect levels of collaboration between parents and 
teachers. The existence of partnership behaviors and the similarity of goals, expectations and ideas are among the aspects that indicate a positive relationship between parents and teachers.

iv. the evaluation of the others' contribution to the relationship. It refers to the personal characteristics of parents and teachers, especially those related to their specific roles that concern their interaction.

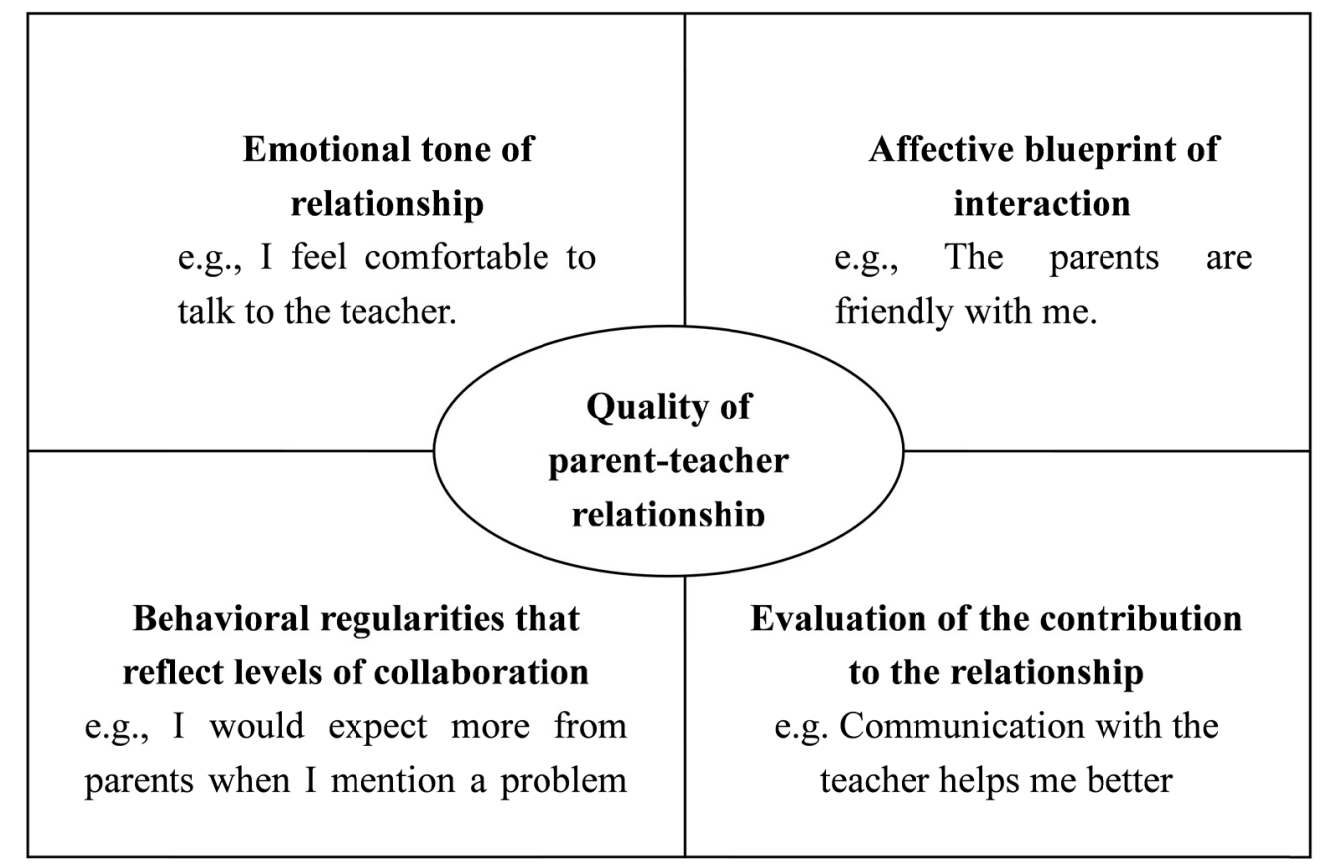

Figure 1. Indicators of the parent-teacher relationship quality

It should be noted that there are no clear boundaries among the aforementioned indicators of the relationship quality between parents and teachers. This is especially useful however for the operational specification of these categories in order to empirically assess the structure of parent-teacher relationship quality.

\subsection{The Purpose of the Study}

Taking into consideration (a) the importance of parent-teacher relationship and its quality in children's academic and social development, especially during the early years, (b) the lack of a measurement during the kindergarten's period and (c) on the grounds of the new developments in the Greek kindergarten national curriculum concerning family-school interaction together with (d) the lack of empirical data to describe how the stakeholders responded to these new mandates, we delivered a study aiming to capture parents' and kindergarten teachers' beliefs about the affective aspects of their interaction, through the development of the "Quality of Parent-Teacher Relationship Scale in the Kindergarten" (QPTRS-K; Penderi, 2012), as well as the congruence between their perceptions. Further evidence concerning reliability and validity of the new scale was studied through the examination of association with other variables from the family and kindergarten setting. 


\section{Method}

\subsection{Participants}

In this study 913 mothers, of 441 (48\%) boys and 472 (52\%) girls of Greek speaking families attending full day (42\%) and half day (58\%) kindergarten classes, and 233 kindergarten teachers, randomly selected, participated in the study. The participants were recruited through a stratified sampling procedure from 33 prefectures (out of 53 in total) representing the 13 regions of the country. Eighty-nine (38\%) kindergartens were based in metropolitan urban areas, $42(18 \%)$ in urban areas, $61(26 \%)$ in semi-urban and $41(18 \%)$ in rural areas. Mothers' mean age was 35 years old ( $s d=4.66$; range: $22-54$ years) and kindergarten teachers' mean age was 41 years old ( $s d=7.70$; range: $24-58$ years $)$ with an average teaching experience of 14 years ( $s d=9.05$; range: $1-35$ years).

\subsection{Procedure}

All the kindergartens teachers were contacted by the second author and were informed about the research purposes and process. Teachers were asked to randomly choose 4 children from their classroom (only of Greek speaking family background) and, in turn, to ask their mothers if they were willing to participate in the study. A letter containing a more comprehensive description of the study and requesting permission to contact families was mailed to mothers. Following their consent to participate questionnaires were sent and returned either in person or by post. Return rate reached almost $94 \%$.

\subsection{Measures}

Quality of Parent-Teacher Relationship Scale in the Kindergarten (QPTRS-K)-Parent and Teacher forms (Penderi, 2012). This scale was designed on the basis of the four aforementioned indicators of the quality of parent-teacher relationship proposed in this study and includes two equivalent forms in terms of the constituent items. It comprised 20 items that were selected from a larger initial pool of items presented in other relevant instruments such as Elicker's Parent Caregiver Relationship Scale (PCRS; Elicker, Noppe, Noppe, Fortner-Wood, 1997) and Vickers and Minke's (1995) Parent Teacher Relationship Scale (PTRS) as well as from formerly conducted interviews with mothers and kindergarten teachers. The scale was tested in two pilot studies that allowed for item refinement. Respondents rated each item on a five-point Likert type scale ranging from 1 (strongly disagree) to 5 (strongly agree). Eleven (11) items were negatively worded, which were reverse-scored before analysis, so that higher score reflects positive characteristics of parent-teacher relationship.

\subsubsection{Family Context Variables}

Parents' Report Questionnaire (PRQ) (Dibble \& Cohen, 1974). The scale is consisted of 16 categories of parental behaviours that represent parenting styles, 8 of which reflect the positive or socially desirable interaction with the child while the remaining 8 categories describe the negative or socially undesirable interaction with the child. Each category is represented by 3 items. A 7-point Likert type scale ranging from 0 (never) to 6 (always) is 
used to rate the frequency of occurrence of each behaviour according to respondents. Two broad dimensions of parenting style arise, positive and negative parenting, when the scores of the three items that constitute each category are summated and each cattegory represents a variable (Dibble \& Cohen, 1974). Although authors did not report information regarding the reliability and validity testing, other researchers have provided evidence for the factorial structure and internal consistency of a short form of the measure (e.g., Sigal et al., 2003).

The PRQ was chosen in the study as: a) it focuses on the developmental period targeted in the present study, b) the behaviours described seemed to be appropriate with reference to the Greek context and c) there has been evidence in the literature concerning the reliability and validity of the scale.

For the purposes of the present study a short version of the questionnaire was used including 10 (sensitivity to feeling, positive involvement, shared decision making, acceptance of autonomy, positive discipline, control through anxiety, control through guilt, control through hostility, withdrawal of relationship, intrusiveness) out of the 16 behavioural categories, developed after pilot testing. Internal consistency was satisfactory for the two factors of the positive and negative parenting ( $a=.75$, for both subscales).

Parenting Sense of Competence (Wallstone \& Wandersman, 1978). The scale is composed by 17 items that reflect parents' sense of general efficacy from their parenting role. A 6-point Likert type scale ranging from 1 (strongly agree) to ...6 (strongly disagree) is used to capture respondents' level of agreement with each statement. Johnston and Mash (1989) indicated two reliable factors that reflect Efficacy (Cronbach $a=.75$ ) and Satisfaction (Cronbach $a=.76$ ) in parenting role explaining $36 \%$ of the total variance. Satisfactory internal consistency was also reported for total scale (Cronbach $a=.79$ ). The high level of consistency reported in the literature was one of the reasons for including the particular scale in the study plan. Items wording seems to correspond to a variety of socio-economic contexts and developmental periods (Coleman \& Karraker, 2000).

In the present study all the items seemed to adequately load on the two suggested factors. Cronbach alphas for Efficacy and Satisfaction subscales as well as overall scale was .75, .72 and .76, correspondingly indicating satisfactory levels of internal consistency.

\subsubsection{Kindergarten Context Variables}

Kindergarten Teachers' Job Satisfaction Scale (KTJSS) (Hammarberg, 2003). The scale is consisted of 12 items that are used to capture caregivers' satisfaction with "working condition in preschool, in general" (Hammaberg, 2003, p. 22), using a 5-point Likert type responses from 1 (Strongly Disagree) to 5 (Strongly Agree). The scale has indicated high levels of internal consistency for total scale (Cronbach $a=.82$ ). For the current study a slightly moderated version was used so that to match the working conditions in Greek kindergartens. Factor analysis extracted two reliable factors: (a) Satisfaction from working duties and work load (7 items) and (b) Satisfaction from working environment (5 items). The scale showed high levels of internal consistency for both the subscales (Cronbach alphas were.82 and .70, respectively) and the total scale $(a=.79)$. The KTJSS was one of the few measures 
concerning job satisfaction beliefs in the preschool. It consists of dimensions that were evidenced in the relevant literature and the items capture aspects that concern both specific and general dimensions of the working context.

Teaching Efficacy Scale (TES) Short Form (Hoy \& Woolfolk, 1993). It consists of 10 items that are answered in a 6-point rating scale ranging from 1 (strongly agree) to 6 (strongly disagree) representing respondents' level of agreement with each sentence. The scale extracts two factors: (a) personal teaching efficacy: refers to teachers' perceptions of their ability to fulfil their teaching duties and have positive outcomes to students (Cronbach $\alpha$ : .77); (b) general teaching efficacy: focuses on the influence of external factors, such as the family environment, in the effectiveness of the teaching practices (Cronbach $\alpha$ : .72). As the two factors interpret two conceptually different structures (Ghaith \& Yaghi, 1997), data from the subscales was used in the present study. Internal consistency for both factors was satisfactory ( $a=.78$ and .68 for personal and general teaching efficacy, respectively). The fact that the scale is one of the most popular tools in the relevant literature and the high levels of reliability and validity reported in the literature were among the criteria for including the TES in the study.

Survey questionnaire. In addition, a set of questions concerning demographic characteristics designed for mothers and kindergarten teachers were included in the questionnaire.

\section{Results}

\subsection{Descriptive (Item) Statistics of the QPTRS-K (Parent and Teacher Form)}

Items in both, parent and teacher, forms showed high variability as all of them, apart from item 2 in mother form and items 2 and 12 in teacher form, used the full range of possible scores ranging from 1 (strongly disagree) to 5 (strongly agree). The highest mean in parent form was 4.61 ( $S D=.56)$ (item 2 ) and the lowest $3.63(S D=1.26)$ (item 18). In teacher the form the highest mean was $4.30(S D=.70)$ (item 12) and the lowest $2.83(\mathrm{SD}=1.10)$ (item 13).

All the items in both forms seemed to contribute to the internal consistency of the scale after testing Cronbach's alpha if item deleted. Item-total correlations ( $r=.33-.67$ and $r=.32-.69$ for mother and teacher form respectively) were indicative of the cohesion of the scale and at the same time they provided evidence for the lack of conceptual overlap among the items. The negative correlations of the items with negative wording with the rest of the items in the scale provided evidence for the conceptual structure of the measure.

\subsection{Factor Analysis of the QPTRS-K (Parent and Teacher Form)}

To determine the presence of the underlying latent structure accounting for common variance of the kindergarten teachers' and mothers' perceptions concerning the mode of their interaction were subjected to a series of exploratory latent structure analyses.

To determine the construct validity of the 20-item QPTRS-K scale, for parent and teacher form, a series of principal component analyses were performed, as the purpose was the detection of the dimensions that constitute the nature of the quality of parent-teacher relationship and the reduction of variables by grouping items into factors (Tacq, 1997). With respect to rotation method, Brown's 
(2009) suggestion was followed concerning the examination of the factor correlation matrix after requesting for oblique procedure. As indicated, if correlations exceed .32 then there is enough variance ( $10 \%$ and more) to justify oblique rotation which was finally the case in the current study (.58 and .60 for parent and teacher form, respectively) following the initial analysis using the promax method (Abdi, 2003; Ford, MacCallum, \&Tait, 1986).

A number of decision rules were used to determine the number of factors to be retained reflecting the most parsimonious factor solution:(a) the Kaiser (K1) criterion rule of eigenvalues greater than 1 (Guttman, 1954); (b) the inspection of the screeplot, i.e. Cattell's scree test (Cattell, 1966); (c) Velicer's (1976) minimum average partials (MAP); (d) the use of Horn's (1965) parallel analysis (HPA) (see also Buja \& Eyuboglu, 1992); (e) retention of at least three items per factor with salient loadings, where loadings $>.30$ are considered salient; (f) demonstration of adequate internal consistency for each factor, with alpha coefficients $>0.70$; (g) avoiding "cross-loading" items (i.e. multiple salient factor loading) and (h) holding simple structure (mutually exclusive assignment of items to factors with the maximum number of items retained).

The correlation matrix of both versions of QPTRS-K items was factorable since a number of criteria were met: (a) there were several correlations above .30 (Tabachnick \& Fidell, 2007), (b) the Kaiser-Meyer-Olkin Measure of Sampling Adequacy (Kaiser, 1974) had a value of .937 and .915 for parent and teacher form, far exceeded the minimum standard of .60 (Kaiser, 1974; Kline, 1994; Tabachnick \& Fidell, 2007), and (c) Bartlett's Test of Sphericity (Bartlett, 1950, 1954) was statistically significant for both forms (parent form: $\chi^{2}=6737.01$, $d f=190, p<.001$; teacher form: $\left.\chi^{2}=1599.81, d f=190, p<.001\right)$ suggesting a reasonable level of correlation between the items of the scale.

The initial analyses indicated that in parent form, three factors had eigenvalues greater than 1 but only two of them explained almost $10 \%$ (or more) of the variance. In teacher form, there were five factors having eigenvalues exceeding 1 but only one actually explained at least $10 \%$ of the variance. Applying the above mentioned criteria a two factor solution seemed better interpretable and conceptually meaningful.

Each of the two factors consisted of more than five items, suggesting a robust structure (Costello \& Osborne, 2005) while loadings exceeded the saliency criterion of $\geq .3$ (Boyle, 1985; Brown, 2009; Tinsley \& Tinsley, 1987). Total variance explained by the two factors was $46.23 \%$ and $43.06 \%$ for parent and teacher form, correspondingly. The composition of the two subscales differed in parent (Table 1) and teacher (Table 2) forms but was similarly interpreted. 


\section{Macrothink}

Table 1. Parent QPTRS-K factor analysis $(\mathrm{N}=913)$

\begin{tabular}{|c|c|c|}
\hline \multirow{2}{*}{ QPTRS-K-P } & \multicolumn{2}{|c|}{ Factors } \\
\hline & Trust & Communication \\
\hline $\begin{array}{l}17 \text { I admire the way the kindergarten teacher works with the } \\
\text { children }\end{array}$ & .77 & .44 \\
\hline 19 The kindergarten teacher understands me & .74 & .44 \\
\hline 1 The kindergarten teacher does what is necessary for my child & .71 & .48 \\
\hline 2 The kindergarten teacher is friendly & .70 & .34 \\
\hline 14 I feel comfortable to talk to the kindergarten teacher & .69 & .38 \\
\hline $\begin{array}{l}9 \text { The kindergarten teacher teaches my child the right things to } \\
\text { start primary school }\end{array}$ & .68 & .38 \\
\hline 5 The kindergarten teacher is consistent in what she says and does & .67 & .39 \\
\hline 7 The kindergarten teacher is interested in listening to me & .67 & .39 \\
\hline $\begin{array}{l}12 \text { Communication with the kindergarten teacher helps me better } \\
\text { understand my child }\end{array}$ & .56 & .27 \\
\hline $\begin{array}{l}11 \text { I have similar beliefs with the kindergarten teacher about the } \\
\text { child' behavior }\end{array}$ & .37 & .76 \\
\hline $\begin{array}{l}15 \text { I have similar beliefs with the kindergarten teacher about what } \\
\text { can the child achieve }\end{array}$ & .40 & .74 \\
\hline $\begin{array}{l}6 \text { I have similar beliefs with the kindergarten teacher about } \\
\text { discipline methods }\end{array}$ & .39 & .74 \\
\hline $\begin{array}{l}20 \text { I have similar beliefs with the kindergarten teacher about what } \\
\text { should my child learn }\end{array}$ & .51 & .73 \\
\hline $\begin{array}{l}13 \text { The kindergarten teacher is responsive when I mention a } \\
\text { problem with my child }\end{array}$ & .55 & .70 \\
\hline 16 The kindergarten teacher informs me about the program & .61 & .68 \\
\hline $\begin{array}{l}8 \text { The kindergarten teacher informs me about how to participate } \\
\text { and help in the classroom }\end{array}$ & .57 & .67 \\
\hline $\begin{array}{l}3 \text { I have similar expectations with the kindergarten teacher about } \\
\text { the child }\end{array}$ & .35 & .64 \\
\hline $\begin{array}{l}10 \text { I feel I am doing a good job with my child when I talk with the } \\
\text { kindergarten teacher }\end{array}$ & .13 & .56 \\
\hline $\begin{array}{l}4 \text { The kindergarten teacher communicates with me not only when } \\
\text { there is a problem }\end{array}$ & .29 & .44 \\
\hline 18 I exchange warm greetings with the kindergarten teacher & .38 & .42 \\
\hline
\end{tabular}


Table 2. Teacher QPTRS-K factor analysis $(\mathrm{N}=233)$

\begin{tabular}{|c|c|c|}
\hline \multirow{2}{*}{ QPTRS-K-T } & \multicolumn{2}{|c|}{ Factors } \\
\hline & Trust & Communication \\
\hline 7 Parents in my class show interest in listening to me & .73 & .33 \\
\hline 1 Whatever the child needs, I trust parents & .71 & .51 \\
\hline $\begin{array}{l}9 \text { I trust parents to help the children prepare for the } \\
\text { primary grades }\end{array}$ & .68 & .53 \\
\hline $\begin{array}{l}5 \text { Parents in my class are consistent in what they say } \\
\text { and do }\end{array}$ & .67 & .50 \\
\hline 19 I feel that parents in my class understand me & .65 & .61 \\
\hline 14 I feel comfortable to talk to the parents in my class & .65 & .24 \\
\hline 2 Parents in my class are friendly & .65 & .28 \\
\hline $\begin{array}{l}4 \text { Parents in my class communicate with me not only } \\
\text { when there is a problem }\end{array}$ & .61 & .38 \\
\hline $\begin{array}{l}8 \text { Parents in my class inform me about family } \\
\text { routines }\end{array}$ & .61 & .53 \\
\hline $\begin{array}{l}16 \text { Parents in my class inform me about the children's } \\
\text { progress }\end{array}$ & .60 & .52 \\
\hline $\begin{array}{l}17 \text { I admire the way parents in my class raise their } \\
\text { children }\end{array}$ & .58 & .48 \\
\hline $\begin{array}{l}18 \text { I exchange warm greetings with the parents in my } \\
\text { class }\end{array}$ & .50 & .29 \\
\hline $\begin{array}{l}12 \text { Communication with the parents in my class helps } \\
\text { me better understand the children }\end{array}$ & .39 & .13 \\
\hline $\begin{array}{l}10 \text { I feel I am doing a good job with the children } \\
\text { when I talk with the parents in my class }\end{array}$ & .34 & .31 \\
\hline $\begin{array}{l}20 \text { I have similar beliefs with the parents in my class } \\
\text { about what should the children learn }\end{array}$ & .47 & .78 \\
\hline $\begin{array}{l}6 \text { I have similar beliefs with the parents in my class } \\
\text { about discipline methods }\end{array}$ & .41 & .75 \\
\hline $\begin{array}{l}13 \text { The parents in my class are responsive when I } \\
\text { mention a problem with the children }\end{array}$ & .63 & .71 \\
\hline $\begin{array}{l}11 \text { I have similar beliefs with the parents in my class } \\
\text { about the children's behavior }\end{array}$ & .43 & .70 \\
\hline $\begin{array}{l}15 \text { I have similar beliefs with the parents in my class } \\
\text { about what can the children achieve }\end{array}$ & .21 & .64 \\
\hline $\begin{array}{l}3 \text { I have similar expectations with the parents in my } \\
\text { class about the children }\end{array}$ & .29 & .62 \\
\hline
\end{tabular}

The first factor was labeled Trust/Acceptance and seemed to reflect the three (emotional tone, affective blueprint and contribution to the relationship) of the four aforementioned indicators of the quality of parent-teacher relationship. It included 9 items $(17,19,2,1,14,9,5,7$ and 
12) for parent form and 14 items $(7,14,2,1,5,9,4,19,8,16,17,18,12$ and 10) for teacher form. The second factor, Communication/Responsiveness, described the levels of collaboration between parents and teachers. It comprised 11 items $(11,6,15,20,3,13,10,8$, 16 and 4) for parent form and 6 items $(20,6,15,11,3$ and 13) for teacher form. It should be noted that 15 items $(75 \%)$ loaded on similar factors in parent and teacher forms.

\subsection{QPTRS-K (Parent and Teacher Form) Reliability}

To provide evidence for the internal consistency of the measure, Cronbach's alpha was estimated for the total scale and the subscales for parent and teacher forms. The QPTRS-K showed the same high levels of internal consistency for both parent and teacher forms $(a=.90)$. The first factor, Trust/Acceptance, had the same high alpha for both forms $(a=.86)$. The second factor, Communication/Responsiveness, showed also high levels of internal consistency ( $a=.85$ and .81 for parent and teacher form respectively).

\subsection{Further Evidence for QPTRS-K (Parent and Teacher Form) Validity: Correlations with other Contextual Variables}

Following Elicker's et al. (1997) suggestions we examined the QPTRS-K (parent and teacher form) correlations with other measures from the two principal contexts (family and kindergarten) since a number of associations were expected according to theory.

\subsubsection{QPTRS-K-Parent Form}

Mothers' age was not related to their perceptions about the quality of their relationship with their child's kindergarten teacher (see Table 3). Mothers' positive parenting (PRQ) seemed to be highly correlated with QPTRS-K total scale and subscales indicating that the more positive is mother's interaction with the child the more trusting and responsive is the relationship with the child's kindergarten teacher, according to mothers' responses. Mothers' negative parenting scores (PRQ) exhibited significant negative correlations with QPTRS-K total scale and Communication subscale. When the emotional climate of mother-child interaction is negative, mothers tend to evaluate their general relationship and their communication with the kindergarten teacher more negatively than mothers with a positive parenting style. Finally, the greater the amount of experience the children seemed to have in the day-care, the more negative was their perception of their relationship with the kindergarten teacher.

Table 3. Parent QPTRS-K correlations with child and family context variables

\begin{tabular}{lccc}
\hline & QPTRS-K(P) & $\begin{array}{c}\text { Trust } \\
\text { Subscale }\end{array}$ & $\begin{array}{c}\text { Communication } \\
\text { Subscale }\end{array}$ \\
\hline Mother's age & .02 & .04 & .02 \\
Positive Parenting & $.21^{* *}$ & $.20^{* *}$ & $.18^{* *}$ \\
Negative Parenting & $-.10^{* *}$ & .02 & $-.16^{* *}$ \\
PSOC & $.19^{* *}$ & $.09^{*}$ & $.22^{* *}$ \\
Experience in day-care (in months) & $-.10^{*}$ & $-.12^{* *}$ & -.08 \\
\hline
\end{tabular}


The relation between mothers' QPTRS-K total scale and subscales and their reports on PSOC total scale was positive. In other words, it seems that the more mothers feel efficacious in their parenting role and are satisfied from their engagement into the parenting duties they report more positive believes about the quality of their relationship with the kindergarten teachers, especially with reference to their communication, trusting behaviours and teachers' responsiveness.

\subsubsection{QPTRS-K-Teacher Form}

Unlike mothers, teachers' age was positively related to teachers' perceptions of the quality of interaction with mothers concerning the Trust subscale and the QPTRS-K total scale (see Table 4). Teaching experience was also related to Trust subscale. Child temperament dimensions showed some significant but negative correlations with Communication subscale and QPTRS-K total scale. More specifically, the higher the score in Sociability and Activity dimension, according to mothers' ratings, the less positive were teachers' perceptions of Communication with mothers. Kindergarten teachers' job satisfaction (total scale) and their perceptions of General teaching efficacy were highly and positively related to their QPTRS-K total scale and subscale ratings. Personal teaching efficacy was moderately correlated to Trust subscale.

Table 4. Teacher QPTRS-K correlations with child and kindergarten setting variables

\begin{tabular}{lccc}
\hline & QPTRS-K(T) & $\begin{array}{c}\text { Trust } \\
\text { Subscale }\end{array}$ & $\begin{array}{c}\text { Communication } \\
\text { Subscale }\end{array}$ \\
\hline Teaching experience & .09 & $.15^{*}$ & -.04 \\
Number of children in the classroom & $-.15^{*}$ & $-20^{* *}$ & -.02 \\
Teacher's age & $.13^{*}$ & $.18^{* *}$ & .02 \\
Teacher Job Satisfaction (total scale) & $.38^{* *}$ & $.35^{* *}$ & $.28^{* *}$ \\
Personal Teaching Efficacy & .11 & .01 & $.16^{*}$ \\
General Teaching Efficacy & $.22^{* *}$ & $.20^{* *}$ & $.19^{* *}$ \\
\hline
\end{tabular}

\subsection{Congruence of Mothers and Kindergarten Teachers'Ratings and Differences in Scores}

The only significant correlation between parent and kindergarten teachers' total scale and subscales was that of the total scale scores that seemed to be positively related $(r=.14, d f=222$, $p<.05$ ). The more positive is mothers' general emotional and affective impression of their interaction with kindergarten teachers, the more optimal are teachers" beliefs about the relationship they develop with mothers.

Kindergarten teachers $(\mathrm{M}=70.01, \mathrm{SD}=9.89)$ seemed to perceive in a less positive way their relationship with parents $(t=-15.41, d f=1113, p<.001)$ compared to mothers' perceptions concerning their interaction with teachers $(\mathrm{M}=81.98, S D=10.52)$. More specifically, teachers $(\mathrm{M}=32.73, S D=4.37$ and $\mathrm{M}=37.36, S D=6.39$, respectively) have lower scores than mothers $(\mathrm{M}=38.87, S D=4.55$ and $\mathrm{M}=43.08, S D=7.17$, respectively) not only in the Trust/Acceptance subscale $(t=-18.38, d f=1132, p<.001)$ but also the Communication/Responsiveness subscale $(t=-11.05, d f=1124, p<.001)$. 


\section{Discussion}

The main purpose of the present study was to provide evidence for the reliability and validity of the Quality of Parent-Teacher Relationship Scale for kindergarten (QPTRS-K) (Parent and Teacher Forms) (Penderi, 2012). It is a newly constructed measure that was designed to assess the relational aspects of parent-teacher interaction, using data from a national Greek sample of 913 mothers and 233 kindergarten teachers. To provide evidence for its psychometric properties, a set of other theoretically-related variables from the family and the kindergarten settings was also included to examine the correlation status of QPTRS-K parent and teacher's total scales and subscales.

It was found that both, parent and teacher, scales had very high internal consistency. Two reliable and valid factors emerged that were interpreted similarly for parents and kindergarten teachers, although there were some differences in the distribution of items. The two factor structure of the scale and the meaning of each subscale provided evidence for the two broad dimensions, Trust/Acceptance and Communication, proposed to constitute the concept of parent-teacher relationship quality. The most important factor for both agents, parents and teachers, seemed to be Trust/Acceptance. It consisted of items that reflected the three of the four indicators of the affective component of parent-teacher interaction, the Affective blueprint of interaction, the Emotional tone of relationship and the Evaluation of the other part's contribution to the relationship. These items described stakeholders' sense of partner's trustworthiness and acceptance by the other.

Teachers' Trust/Acceptance subscale included five additional items, compared to the parents' corresponding subscale, which described mainly parent-initiated information exchange. These items represented the Behavioral regularities that reflect levels of collaboration category of quality indicators, proposed in the theoretical section. It seems that for kindergarten teachers the fact that parents initiate communication and share information about the child and family issues does not comport with their notion of collaboration but mostly reveals to them that they are trusted and accepted by parents. The fact that parent school cooperation is organized and managed by the school itself and that teachers frame collaboration according to their own terms not favoring parents' initiatives, is reported in the literature (e.g., Abrams \& Gibbs, 2002; Addi-Raccah \& Arviv-Elyashiv, 2008; Bernhard et al., 1998; Lawson, 2003).

The second factor was named Communication/Responsiveness and contained items, less in number than in teachers' subscale, which reflected the Behavioral regularities that reflect levels of collaboration category of relationship quality indicators. As also indicated by Elicker and associates (1997) a sense of intimacy and affiliation may be cultivated through collaborative behaviors between parents and teachers. Differences in the way parents and teachers perceive specific components of the relational aspect of their interaction, are also evident in Elicker and associates' study (1997). The authors however reported that only 1/3 of the PCRS items loaded on similar factors in parent and caregivers' scales, while the present study supports a more similar structure in mothers and kindergarten teachers' beliefs about their relationship, taking into account that almost $4 / 5$ of the items loaded on similar factors. 
Differences in the frequency and extent of parents' participation in day-care centers and kindergarten, as reported in Manolitsis' study (2004), may explain differences in the structure of partners' believes about their relationship in the two educational settings.

It should be noted that although the total variance explained by the two factors in both parent and teacher's scales is not so high (46\% and $43 \%$ correspondingly), the results are congruent with those provided by Elicker and associates (1997) concerning the factorial structure of the PCRS (the variance explained was $45 \%$ for the parent form and $48 \%$ for the caregiver form respectively).

Incongruence between parents and caregivers' views of their relationship reported in many studies that focus on preschool settings (Elicker et al., 1997; Joshi \& Taylor, 2007; Pirchio, Volpe, \& Taeschner, 2011) and by Mavropoulou (2002) concerning parents and teachers relationship in primary grades in Greece, was not supported by data provided in this study for parents and kindergarten teachers' quality of relationship. It seems that the more positive are mothers' general views of their relationship with kindergarten teachers, the more highly teachers appreciate their connection with parents in their classrooms. This is a very optimistic evidence for family and kindergarten connection which seems to be close, constructive and important for stakeholders that share their views and develop expectations over their objective and subjective emotional and affective interaction experiences.

Contrary to the lack of difference between mean scores attributed by Greek parents and caregivers in PCRS, reported by Renztou (2012), the present study found that mothers have more positive beliefs about their relationship with kindergarten teachers compared to teachers' perceptions of their interaction with parents, as measured with QPTRS-K parents and teachers' forms and their subscales. This finding is in line with evidence provided by a number of relevant international studies that show parents' more optimal views about their children's teachers compared to teachers' perceptions of the families and the relationship they develop with them (Adams \& Christenson, 2000; Owen, Ware, \& Barfoot 2000; Rentzou, 2011; Shpancer, 2002). This optimistic stance towards teachers may reveal parents' need to feel that their children enjoy a proper care and educational services by persons that are qualified, interested, caring and trustworthy. Moreover, parents may feel that when their relationship with teachers is positive and close it would have positive effects in the teacher-child relationship as well and consequently may "polish" their perceptions about their interaction with teachers.

The QPTRS-K parent and teacher scales and subscales showed significant correlations with the majority of the contextual variables that were included in the study and in the assumed direction, except the experience in day-care (in months). It was found that the longer the experience of the child's attendance in day-care, before entering kindergarten, the more negative mothers' believes were about the relationship quality with the kindergarten teacher, concerning the Trust dimension and the total score in QPTRS-K. It seems that mothers may have preconceptions about their relationship with kindergarten teachers, as a result of their negative earlier experiences from preschool, and they are more cautious and suspicious against kindergarten teachers. This finding is intriguing and it needs further examination. 
Mothers' age did not correlate with their perceptions of the relationship quality with teachers, congruent to Pirchio, Volpe and Taeschner's (2011) findings.

Mothers' perceptions of the quality of relationship with teachers were positively correlated with the positive interaction style with the child and their sense of competence in their parenting role and negatively with the negative parenting style. These findings provide evidence for the importance of close, worm and trusting relationships between family and school as an optimal factor in family functioning.

Kindergarten teachers' perceptions of Trust in relationship with parents were positively linked to their teaching experience and age, a factor that also seemed to influence their general beliefs about their relationship with parents (total scale scores). This is a very important and optimistic aspect in parent-teacher relationship as it seems that experience in the profession as well as personal maturation help teachers develop communication skills, tolerance, empathy and understanding that make them more flexible, efficient and constructive in contacting with parents. Brouzos (2002) provided evidence that teaching experience is actually a factor that influences communication quality with parents, showing that teachers having less than 15 years of teaching experience were facing more problems and difficulties when interacting with parents.

This finding is incongruent with other studies that focus on day-care centers and describe a negative link between caregivers' age and teaching experience and their perceptions of relationship quality with parents as measured with PCRS (Rentzou, 2011). However, despite the discrepancy in the direction of the relation, in both studies it is evident that personal growth and maturation is a stronger factor in the development of parent-teacher/caregiver relationship than professional experience. This finding may have implications for teachers and caregivers' in-service training and professional development concerning especially the sensitive issue of connection with the children's families, as indicated by other researchers and educational theorists (e.g. Gliaou-Christodoulou, 2006).

Larger groups were related to more negative kindergarten teachers' perceptions concerning Trust and lower general quality of relationship with parents (QPTRS-K total score). The significance of the number of children in the classroom for the development of teachers' views about their interaction with parents was also evidenced with reference to the Greek (Rentzou, 2011) and the American (Elicker et al., 1997) day-care centers, although in the second case there was a positive correlation. Results in the present study show that in large group size lower quality relationships exist between parents and teachers, which is an indicator of lower overall quality in educational settings (Petrogiannis, 2006).

The fact that kindergarten teachers' job satisfaction and teaching efficacy beliefs seemed to have positive links with their judgments about relationship quality with parents, highlights the importance of building collaboration with families for the professional development of teachers. Data may also have implications for the improvement of the professional environment and working conditions as well as for the continuous reinforcement of the general teaching skills as a means to promote teachers' overall working attitude and specific stance towards parents. Relevant evidence concerning the link between teachers' job 
satisfaction and the quality of interaction with parents was provided for day-care in Elicker and associates' study (1997).

The uniqueness of parent-teacher relationship in the kindergarten was supported by findings in this study that highlight particular characteristics in the quality of mothers and kindergarten teachers' interaction, compared to relevant evidence provided for other educational settings, especially preschool and elementary level. Results have implications for both research and policy. The development of a measure that takes into account the developmental characteristics of parent-teacher quality and permits longitudinal assessment across educational settings and levels could be useful in order to promote knowledge and understanding of the complex issue of parent-teacher connection. Moreover, the QPTRS-K was developed in Greece and was tested with a Greek sample of mothers and kindergarten teachers. The use of the scale with other Greek and international samples would provide additional data for the psychometric properties of the scale and its appropriateness to capture the quality of relationship between parents and kindergarten teachers regardless the socio-cultural and linguistic background in an attempt to gather and compare evidence that could be used to improve educational policies and programs.

Future research should also focus on the relation between stakeholders' practices for involvement and interaction and the quality of relationships as well as the effects on children's developmental and educational attributes.

\section{References}

Adams, K. S., \& Christenson, S. L. (2000). Trust and the family-school relationship examination of parent-teacher differences in elementary and secondary grades. Journal of School Psychology, 38, 477-497. http://dx.doi.org/10.1016/S0022-4405(00)00048-0

Addi-Raccah, A., \& Ainhoren, R. (2009). School governance and teachers' attitudes to parents' involvement in schools. Teaching and Teacher Education, 25, 805-813. http://dx.doi.org/10.1016/j.tate.2009.01.006

Alevriadou, A., Vriniotis, K., Kiridis, A., Sivropoulou-Theodosiadou, E., \& Chrisafidis, K. (2008). Guide for the full-day kindergarten. Athens: Patakis. [in Greek]

Angelides, P., Theophanous, L., \& Leigh, J. (2006). Understanding teacher-parent relationships for improving pre-primary schools in Cyprus. Educatiomal Review, 58(3), 303-316. http://dx.doi.org/10.1080/00131910600748315

Baker, A. (1997). Improving parent involvement programs and practice: A qualitative study of parent perceptions. School Community Journal, 7(1), 127-153.

Boyle, G. J. (1985). A reanalysis of the higher-order factor structure of the Motivation Analysis Test and the Eight State Questionnaire. Personality \& Individual Differences, 6, 367-374. http://dx.doi.org/10.1016/0191-8869(85)90061-3

Bronfenbrenner, U. (1992). Ecological systems theory. In R. Vasta (Ed.), Annals of child development. Six theories of child development: Revised formulations and current issues (pp. 
187-249). London: Jessica Kingsley.

Bronfenbrenner, U. (1986). Ecology of the family as a context for human development: $\begin{array}{llll}\text { Research perspectives. Developmental } & \text { Psychology, 22, }\end{array}$ http://dx.doi.org/10.1037/0012-1649.22.6.723

Brouzos, A. (2002). Teachers' perceptions about home-school partnership. In Hellenic Pedagogical Society, Greek Pedagogical and Educational Research. Paper presented at the $2^{\text {nd }}$ Conference of the Hellenic Educational Society, Athens 2-4 November 2000. Retrieved by

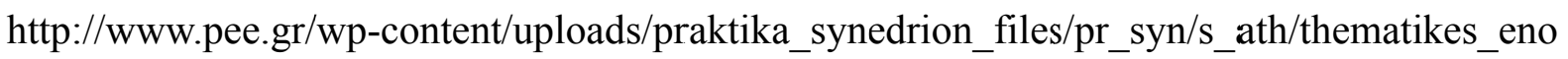
thtes/x/x/x_mproyzos_andreas.htm (19/9/2013) [in Greek]

Christenson, S. (2002). Families, educators, and the family-school partnership: Issues or opportunities for promoting children's learning competence? Paper prepared at the Invitational Conference "The Future of School Psychology", November 14-16, Indianapolis, Indiana.

Christenson, S. (2004). The family-school partnership: An opportunity to promote the learning competence of all students. School Psychology Review, 33(1), 83-104.

Christenson, S., \& Sheridan, M. (2001). Schools and families: Creating essential connections for learning. New York: Guilford Press.

Coleman, P. K., \& Karraker, K. H. (2000). Parenting self-efficacy among mothers of school-age children: Conceptualization, measurement, and correlates. Family Relations, 49, 13-24. http://dx.doi.org/10.1111/j.1741-3729.2000.00013.x

De Schipper, C., Tavecchio, L., Van IJzendoorn, M., \& Van Zeijl, J. (2004). Goodness-of-fit in center day care: relations of temperament, stability, and quality of care with the child's adjustment. Early Childhood Research Quarterly, 19, 257-272. http://dx.doi.org/10.1016/j.ecresq.2004.04.004

Erb, C. S. (2002). The emotional whirlpool of beginning teachers' work. Paper presented at the Annual Meeting of the Canadian Society of Studies in Education, Toronto, Canada.

Gliaou-Christodoulou, N. (2005). The need for training teachers in the direction of development of effective school-family cooperation. Inspection of Educational Issues, 10, 74-83. [in Greek]

Hargreaves, A. (2001). Emotional geographies of teaching. Teachers College Record, 103(6), 1056-1080. http://dx.doi.org/10.1111/0161-4681.00142

Hargreaves, A. (2000). Mixed emotions: Teachers' perceptions of their interactions with students. Teaching and Teacher Education, 16, 811-826. http://dx.doi.org/10.1016/S0742-051X(00)00028-7

Hinde, R. (1995). A suggested structure for a science of relationships. Personal Relationships, 2, 1-15. http://dx.doi.org/10.1111/j.1475-6811.1995.tb00074.x

Hughes, J., \& Kwok O. (2007). Influence of student-teacher and parent-teacher relationships 
on lower achieving readers' engagement and achievement in the primary grades. Journal of Educational Psychology, 99, 39-51. http://dx.doi.org/10.1037/0022-0663.99.1.39

Hujala, E., Turja, L., Gaspar, M., Veisson, M., \& Waniganayake, M. (2009). Perspectives of early childhood teachers on parent-teacher partnerships in five European countries. European Early Childhood Education Research Journal, 17(1), 57-76. http://dx.doi.org/10.1080/13502930802689046

Lasky, S. (2000). The cultural and emotional politics of parent-teacher interaction. Teaching and Teacher Education, 16(8), 843-860. http://dx.doi.org/10.1016/S0742-051X(00)00030-5

Mannan G., \& Blackwell J. (1992). Parent involvement: Barriers and opportunities. The Urban Review, 24(3), 219-226. http://dx.doi.org/10.1007/BF01108494

Marcon, R. A. (1999). Positive relationships between parent school invollvement and public school inner-city preschooler's development and academic performance. The School Psychology Review, 28(3), 395-412.

Mikulincer, M., \& Shaver, Ph. (2005). Attachment theory and emotions in close relationships: Exploring the attachment-related dynamics of emotional reactions to relational events. Personal Relationships, 12, 149-168. http://dx.doi.org/10.1111/j.1350-4126.2005.00108.x

Miretzky, D. (2004). The communication requirements of democratic schools: parent-teacher perspectives on their relationships. Teachers College Record, 106(4), 814-851. http://dx.doi.org/10.1111/j.1350-4126.2005.00108.x

Patrikakou, N., \& Weissberg, P. (2000). Parents' perceptions of teacher outreach and parent involvement in children's education. Journal of Prevention and Intervention in the Community, 20, 103-119. http://dx.doi.org/10.1300/J005v20n01_08

Penderi, E. (2012). Family-school connection in the kindergarten: A study of parental involvement and the factors that influence its development. (Unpublished doctoral dissertation). Department of Education Studies in the Preschool Age, Democritus University of Thrace, Alexandroupolis, Greece. [in Greek]

Petrogiannis, K. (2006). Policy and research on early childcare and education in Greece. In E. C. Melhuish \& K. Petrogiannis (Eds.), Early childhood care and education: International perspectives (pp. 27-41). London: Routledge.

Pianta, R. C., \& Cox, M. J. (1999). The transition to kindergarten. Baltimore, MD: Paul H. Brookes Publishing Company.

Pianta, R. C., \& Walsh, D. J. (1996). High-risk children in schools: Constructing sustaining relationships. New York: Routledge.

Powell, D., Son, S. H., File, N., \& San Juan, R. (2010). Parent-school relationships and children's academic and social outcomes in public school pre-kindergarten. Journal of School Psychology, 48, 269-292. http://dx.doi.org/10.1016/j.jsp.2010.03.002

Rentzou, K. (2012). Quality of care and education provided by Greek day-care centres: An 


\section{Macrothink}

International Research in Education

ISSN 2327-5499

2014, Vol. 2, No. 1

approach from researcher's and early childhood educators' perspective. Early Child Development and Care, 182(10), 1-14. http://dx.doi.org/10.1080/03004430.2012.752736

Reynolds, A. J., Weissberg, R. P., \& Kasprow, W. J. (1992). Prediction of early social and academic adjustment of children from the inner city. American Journal of Community Psychology, 20, 599-624.

Rimm-Kaufman, S. E., \& Pianta, R. C. (2000). An ecological perspective on the transition to kindergarten: a theoretical framework to guide empirical research. Journal of Applied Developmental Psychology, 21, 491-511. http://dx.doi.org/10.1016/S0193-3973(00)00051-4

Sakellariou, M., \& Rentzou, K. (2008). Evaluating provisions for parents and parental involvement in Greek preschool settings. The International Journal of the Humanities, 6(9), 95-106.

Smith, A., \& Hubbard, P. (1988). The relationship between parent/staff communication and children's behavior in early childhood settings. Early Child Development and Care, 35(1), 13-28. http://dx.doi.org/10.1080/0300443880350103

Sutton, R. \& Wheatley, K. (2003). Teachers' emotions and teaching: A review of the literature and directions for future research. Educational Psychology Review, 15(4), 327-358. http://dx.doi.org/10.1023/A:1026131715856

Taylor, L., Clayton, J., \& Rowley, S. (2004). Academic socialization: Understanding parental influences on children's school-related development in the early years. Review of General Psychology, 8(3), 163-178. http://dx.doi.org/10.1037/1089-2680.8.3.163

Tschannen-Moran, M., \& Hoy, W. (2000). A multidisciplinary analysis of the nature, meaning, and measurement of trust. Review of Educational Research, 70(4), 547-593. http://dx.doi.org/10.3102/00346543070004547

\section{Copyright Disclaimer}

Copyright reserved by the authors.

This article is an open-access article distributed under the terms and conditions of the Creative Commons Attribution license (http://creativecommons.org/licenses/by/3.0/). 